\title{
Origical Article
}

\section{Burden of GB Carcinoma among people from Terai, and Hill/ Himalayan regions of Nepal}

\author{
Ganga Sapkota $^{1}$, Dipendra Kumar Mallik ${ }^{1}$, Ashok Sapkota ${ }^{2}$, Sunil Dhakal ${ }^{1}$, Roshan Mishra ${ }^{1}$ \\ BP Koirala Memorial Cancer Hospital, Bharatpur, Nepal.
}

\begin{abstract}
Background: GB carcinoma is rare cancer worldwide, but is sixth most common cancer among females in Nepal. Burden of GB carcinoma has geographical and ethnic variation. This study mainly focuses on geographical distribution of $G B$ carcinoma, among Nepalese patients visiting BPKMCH.

Methods and materials: We conducted a retrospective study approved by Department of GI Surgery, BP Koirala Memorial Cancer Hospital, Bharatpur, Nepal. Datas were collected from Jan 1,2107 to 31 st Dec 2017 from medical record sections. Analysis was completed using SPSS.

Results: A total number of 340 patients were recorded, comprising 220 patients with malignancy and 115 patients with benign lesions, and remaining 5 patients files could not be traced. Among malignant patients 158 were female, and 62 were male, with male to female ratio (M: F) of $1: 2.5$. In malignant group, patients from terai were $70 \%$, hilly and Himalayan region were $30 \%$.

Conclusion: The data provides clue on burden of GB carcinoma being relatively high in female, and terai region of Nepal.
\end{abstract}

Keywords: Medical Record Section, BPKMCH, Geographical Variation, GB Cancer Burden, Terai, Nepal

\section{Introduction}

Gall bladder (GB) cancer was first described in $1777^{(4)}$. GB carcinoma is the fifth most common carcinoma of gastrointestinal tract in United States and most common malignant tumor of biliary tract, representing $46 \%$ of all such malignancies ${ }^{(1)}$. Modern technologies have enhanced the diagnosis of GB malignancy, but still patient presents with advanced stage, due to indeterminate signs and symptoms of disease. The overall mean survival rate for patients with advanced gallbladder cancer is 6 months, with a 5 -year survival rate of $5 \%^{(2)}$. Multiple data have shown marked geographical and ethnic variation in GB carcinoma incidence, being relatively low in Europe and United States, and high among population in Chile, Peru, Mexico and northern India, up to 7.5 per 100,000 in men and 23 per 100,000 in women ${ }^{(3)}$.

The exact etiology of GB carcinoma has not been well appreciated till date, as more than one factor accounts for pathogenesis of this cancer. Many studies have hypothesized GB stone disease and chronic inflammation as an important risk factor in pathogenesis of cancer. Besides, increasing age, female, porcelain $\mathrm{GB}$, adenomatous polyps of $\mathrm{GB}$, chronic infection with
Salmonella typhi, carcinogen exposure, and abnormal pancreatobiliary duct junction are also implicated as risk factor for GB cancer ${ }^{(3,5,6)}$.

GB carcinoma is relatively common in Nepal. The highest frequency for GB carcinoma incidence worldwide is among the female over age 65 (7). In context of Nepal, Pun CB et al., has listed GB carcinoma as sixth most common cancer in females after cervix, breast, lung, ovary, and stomach (8). The incidence of disease is partially determined by social and cultural factors, including beliefs on disease etiology, types of family structure and social support, expectations regarding medical care as well as cumulative lifetime exposure to cancer risk factors. In this retrospective study, we analyze the geographical distribution of gall bladder carcinoma among the patients visiting at BP Koirala Memorial Cancer Hospital (BPKMCH).

\section{Materials \& Methods}

Patients: A retrospective study approved by Department of Surgical Oncology, BP Koirala Memorial Cancer Hospital, Bharatpur, Nepal. The review of records did not require patient approval or informed consent. 
All GB disease cases from January 1st to 31st December 2017 were abstracted from medical record sections in the Hospital based cancer registry of BPKMCH. Patients name, age, sex, address along with clinical diagnosis, radiological findings, tumor markers, histopatholoical diagnosis were recorded. Double/multiple entry cancer cases were excluded by cross checking name, age, sex, address and hospital-registered number of each patient. Methods: Data were entered and analyzed using SPSS and relative frequency were obtained.

\section{Results}

During the study period, a total number of 656 patients were recorded, among whom 335 were seen at our hospital for GB disease, 321 were seen in other hsoptials. This population comprised 220 patients with malignancy and 115 patients with benign lesions. Out of total registered patients 480 were female, and 176 were male. Among malignant patients $72 \%$ (158) were female, and $28 \%(62)$ were male, with male to female ratio (M: F) of 1:2.5. In malignant group, patients from terai were 154 (70\%), hilly and Himalayan region were 66 (30\%). The mean age among malignant group is $53.33 \pm 10.71$.

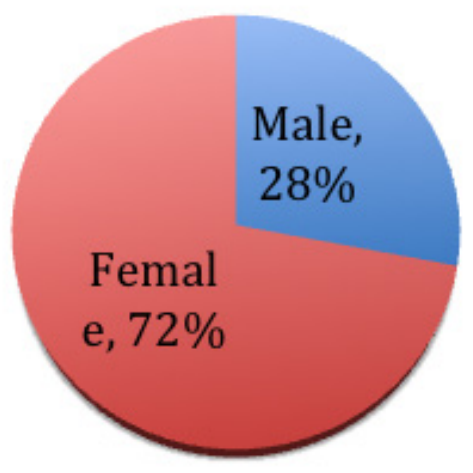

\section{geographical variation}

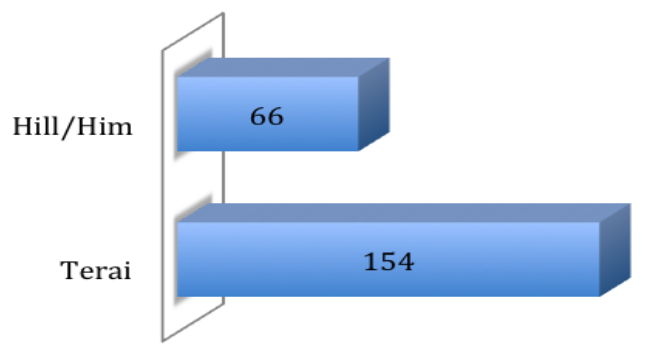

\section{Treatment module}

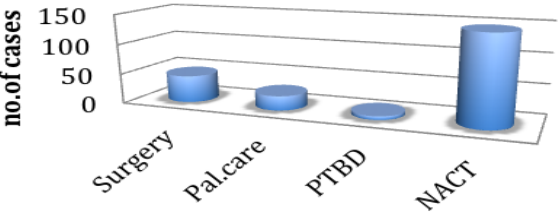

\begin{tabular}{|c|c|c|c|c|}
\cline { 2 - 5 } \multicolumn{1}{c|}{} & Surgery & Pal.care & PTBD & NACT \\
\hline E Series1 & 45 & 24 & 6 & 145 \\
\hline
\end{tabular}

45 patients out of 220 malignant cases underwent surgical treatment, 24 patients were sent for palliative care, 6 patients were advised for PTBD, and 145 patients for Neo-adjuvant chemotherapy.

\begin{tabular}{|l|l|l|l|l|}
\hline SN & \multicolumn{1}{|c|}{ Procedure } & Total & Male & Female \\
\hline 1 & $\begin{array}{l}\text { Radical/Extended } \\
\text { Cholecystectomy }\end{array}$ & 24 & 6 & 18 \\
\hline 2 & Chole with Hepatectomy & 2 & 0 & 2 \\
\hline 3 & $\begin{array}{l}\text { Sub-total/Partial } \\
\text { cholecystectomy }\end{array}$ & 15 & 4 & 11 \\
\hline 4 & $\begin{array}{l}\text { Chole with } \\
\text { Choledochojejunostomy }\end{array}$ & 2 & 1 & 1 \\
\hline 5 & $\begin{array}{l}\text { Chole. with } \\
\text { Choledocholithotomy }\end{array}$ & 2 & 0 & 2 \\
\hline & Total & 45 & 11 & 34 \\
\hline
\end{tabular}

\section{Discussion}

As per our knowledge, this is the first study to address geographical variation in GB carcinoma incidence among Nepalese citizens. Using birthplace, individuals are categorized as citizens from terai, hill and Himalaya. Geographical variation has major impact in the occurrence of cancer pathology, or the risk of disease for individuals living in different area ${ }^{(9)}$. In our study, we have tried to use all available resources, including data from pathology laboratory, operation theatre, to cover the incidence data, despite of biased registration (completeness and induced selection bias), and defects of pathology.

In a multicenter retrospective study by Tamrakar $\mathrm{D}$, et al., out of 150 cases, $72 \%$ were female with male: female ratio of $1: 2.57 ; 84 \%$ of diagnosed GB carcinoma were from terai region and remaining $16 \%$ the hilly regions. (12) In this study, out of 220 malignant cases, 158 were 
female and 62 were male patients. Similarly, $70 \%$ of malignant cases were from terai belt and 30\% from hilly and Himalayan region. Such findings were similar with those of Tamrakar et al. multicenter research, and hence prove female are at higher risk, and in context of Nepal people from terai region are at higher risk of GB carcinoma in compare to hilly and Himalayan regions. Various studies over the years have shown the association of GB carcinoma with geographical and lifestyle factors. Figueiredo et al., have demonstrated GB cancer is more prevalent among individuals consuming diet with high amount of red meat, saturated fat and cholesterol. ${ }^{(13)}$ A population-based study in China showed that incidence of gallbladder cancer was higher among cases with gallstone disease ${ }^{(11)}$. Similarly, a prospective case control study from India showed that chronic typhoid carrier state is important risk factor for carcinoma GB. ${ }^{(10)}$

The present retrospective study showed the prevalence of GB cancer higher in female and majority of cases were from terai region. This findings can be due to higher rate of salmonella infection and intake of diet rich in animal fat which can be attributed to poor water sanitation, personal hygiene and suitable climate for salmonella infections. In context of Nepal, terai region is provided with good infrastructure in transportation, which is supported by favorable geographical landscape, in compare to hilly and Himalayan regions. This could be the likely reason for underreporting of cases from hilly and Himalayan belt in comparison to terai citizens.

There are limitations to this study. Firstly it is a retrospective study, undertaken at single center, and might be insufficiency in determination of geographical variation in GB carcinoma incidence. It would be optimal to design and undertake a prospective and multi-center trial. Secondly, indications for study patient's referrals were varied, and could therefore introduce bias.

In conclusion, our study demonstrated that burden of GB carcinoma is higher in female, and terai belt of Nepal as possible high-risk area for GB carcinoma, which also provides valuable platform for other epidemiological studies.

\section{References:}

1. Jemal A, Siegal R, Ward E, et al. Cancer statistics 2009, CA Cancer J. Clinic; 59:225

2. Stinton LM, Shaffer EA (2012). Epidemiology of gallbladder disease: cholelithiasis and cancer. Gut Liver, 6, 172-87.

3. Wistuba II, Gazdar AF. Gall bladder cancer: lessons from a rare tumour. Nature Rev Cancer.2004;4:695

4. Nevin JE. Carcinoma of the gall bladder. Cancer 1976;37:141-148.

5. Pandey M, Shukla VK. Lifestyle, parity, menstrual and reproductive factors and risk of gallbladder cancer. Eur J Cancer Prev.2003;12:269

6. Misra S, Chaturvedi A, Misra NC, et al. Carcinoma of the gall bladder. Lancet Oncol.2003;4:167.

7. Tada M, Yokosuka O, Omata M, Ohto, M,Isono $\mathrm{K}$. Analysis of ras gene mutations in biliaryand pancreatic tumors by polymerase chain reaction and direct sequencing. Cancer 1990;66:930-935.

8. Pun CB, Pradhananga KK, Siwakoti B, et al (2015). Malignant Neoplasm Burden in Nepal - Data from the Seven Major Cancer Service Hospitals for 2012. Asian Pac J Cancer Prev, 16, 8659-63.

9. Nandakumar A, Gupta PC, Gangadharan P, Visweswara RN, Parkin DM (2005). Geographic pathology revisited: development of an atlas of cancer in India. Int J Cancer, 116, 740-54

10. Typhoid carriers among patients with gallstones are at increased risk for carcinoma of the gallbladder. Dutta U, Garg P, Kumar R et al. American Journal of Gastroenterology (2000) 95(3) 784-787

11. Gallstones and the risk of biliary tract cancer: a population based study in China. Hsing AW, Gao YT, Han TQ et al. Br J Cancer. 2007;97(11):1577. Epub 2001 Nov 13

12. D Tamrakar, IS Paudel, S Adhikary, B Rauniyar, PK Pokharel .Risk Factors for Gallbladder Cancer in Nepal - a Case Control Study. 10.14456/ apjcp.2016.115/APJCP.2016.17.7.3447

13. Jane C. Figueiredo, Christopher Haiman, Jacqueline Porcel et al. Sex and ethnic/racial-specific risk factors for gallbladder disease . BMC Gastroenterology (2017) 17:153 DOI 10.1186/s12876-017-0678-6

14. Tada M, Yokosuka O, Omata M, Ohto, M, Isono $\mathrm{K}$. Analysis of ras gene mutations in biliaryand pancreatic tumors by polymerase chain reaction and direct sequencing. Cancer 1990;66:

15. Nevin JE. Carcinoma of the gallbladder.Cancer 1976;37:141-148.

16. Nevin JE. Carcinoma of the gallbladder.Cancer 1976;37:141-148 